\title{
Application of the method based on technological knowledge and expertise for adding the design of a technological process
}

\author{
Piotr Ociepka ${ }^{1, *}$ \\ ${ }^{1}$ Institute of Engineering Processes Automation and Integrated Manufacturing Systems, Faculty of \\ Mechanical Engineering, Silesian University of Technology, ul. Konarskiego 18a, 44-100 Gliwice, \\ Poland
}

\begin{abstract}
The manufacturing process is an important step in creating new products. Market trends cause that this process must be very flexible to facilitate fast and cost-effective adaptation to changing market conditions. Commonly used CNC machine tools, grouped in flexible manufacturing systems, greatly facilitate the rapid adjustment of production to these dynamic changes. The programs for $\mathrm{CNC}$ machine tools could be easily generated using software of the CAM class. It is also easy to change or modify them. However, the technological process itself still must be planned and continuously optimized with respect to each, new produced detail. The paper presents a method, based on the engineering knowledge and experience, designated to assist the technological process preparation. The method, developed by authors, is based on the CBR method. It is the method of problems solving, basing on seeking an analogy (similarity) between the currently being solved task and the previously solved tasks. In the paper is presented the algorithm of this approach and the formalized description of the developed method.
\end{abstract}

\section{Introduction}

The changing market demand and the increasingly shorter "product life cycle" are forcing manufacturers to accelerate the processes of designing and manufacturing. It results that engineers need, carrying out their routine activities, to use more powerful tools that are able to significantly accelerate activities carried out by them. It is important that, at such operations one should keep the acceptable cost of production as well as the required quality and durability of products. With regard to the processes of designing and constructing, there are many advanced and specialized tools of the CAD/CAE class, which allow significantly accelerating the realization of these activities [1-13]. In the case of the manufacturing process are commonly used the flexible manufacturing systems, which in combination with the multi-purpose CNC machines and computer programs of the CAM class, allows quickly and efficiently adapting production systems to the changeable productions schedules. The important and key element, at the stage of new products manufacturing, are: an adequately

\footnotetext{
* Corresponding author: piotr.ociepka@polsl.pl
} 
planned technological process, correctly chosen machine tools and correctly determined machining parameters [14-15]. These activities require from a technologist an extensive knowledge and experience of the implemented machining process. The experience is particularly important in these engineering activities, which is the result of practical application by the technologist the knowledge possessed by him. That is why more and more attempts are being made to automate and facilitate the task performed by a technologist. There are created informatics tools, often based on artificial intelligence methods that support the technological process preparation. In the paper are presented the results of works related with the development of the method based on knowledge and experience for supporting the technological process preparation.

\section{CBR method}

Case Based Reasoning (CBR) is a method of problems solving, basing on engineering experience processing [16-21]. It involves the search for an analogy between the currently solved task and previously solved ones that have been saved in the "case base" of the CBR system. The main advantage of the CBR method is facilitating the process of knowledge and experience acquiring. This process is realized simultaneously with the given solution creating that is when the knowledge of this solution is the most complete.

Another advantage of this method is that the new solution (new case), stored in the CBR database, could be immediately available during solving the following tasks. It is considered with a very simple, yet effective learning process. With the continuous use of such system it gives the opportunity to gather a wide range of technological knowledge and experience in the certain field of work. The other advantage of this method is the possibility of saving also negative cases or solutions that have been proven to be incorrect. This allows avoiding errors during conducting similar tasks in the future.

The process of problems solving, using the CBR method, could be described as a series of actions, which in the literature is called the loop of four R (Retrieval, Reuse, Revision, Retainment) or shortly the $\mathrm{R}^{4}$ model. This cycle is presented in Fig. 1.

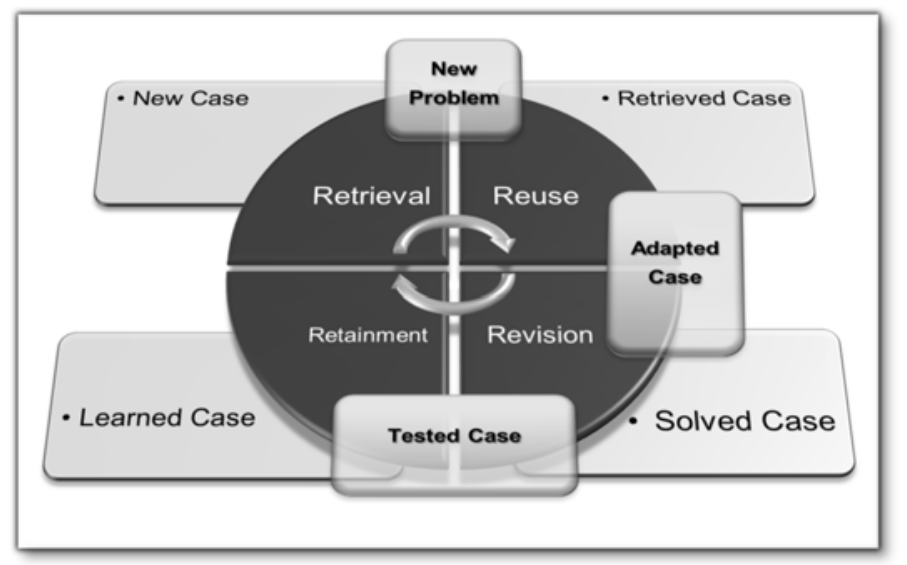

Fig. 1. $R^{4}$ model of the CBR cycle.

\section{Algorithm of functioning of the elaborated method}

The developed method of computer-aided technological process preparation could be included to the group of variants methods. In these methods is used the principle of 
similarity of elements, according to which one could assume that, in the case of elements, characterized by a high degree of technological and constructional similarities one could use, with a high probability, the similar technological processes. The important element of such approach is the adequate description of the technological conditions and the description of the element construction in order to determine the degree of similarity of the analyzed case. In Fig. 2 is shown the algorithm of the system, based on the proposed method, for the manufacturing process.

In the first step is created the description of the technological task. It contains the assumptions for the implemented process. It includes the technological conditions and the description of the construction (geometry, dimensions, tolerances, material) of the analyzed element. On the basis of such description, the CBR reasoning mechanism looks for the most similar case and proposes it as the solution to the problem. In the next stage the technologist could make modifications to the proposed technological process in order to adapt it to the currently analyzed task. Afterwards the adapted technological process could be stored in the CBR database as a new case.

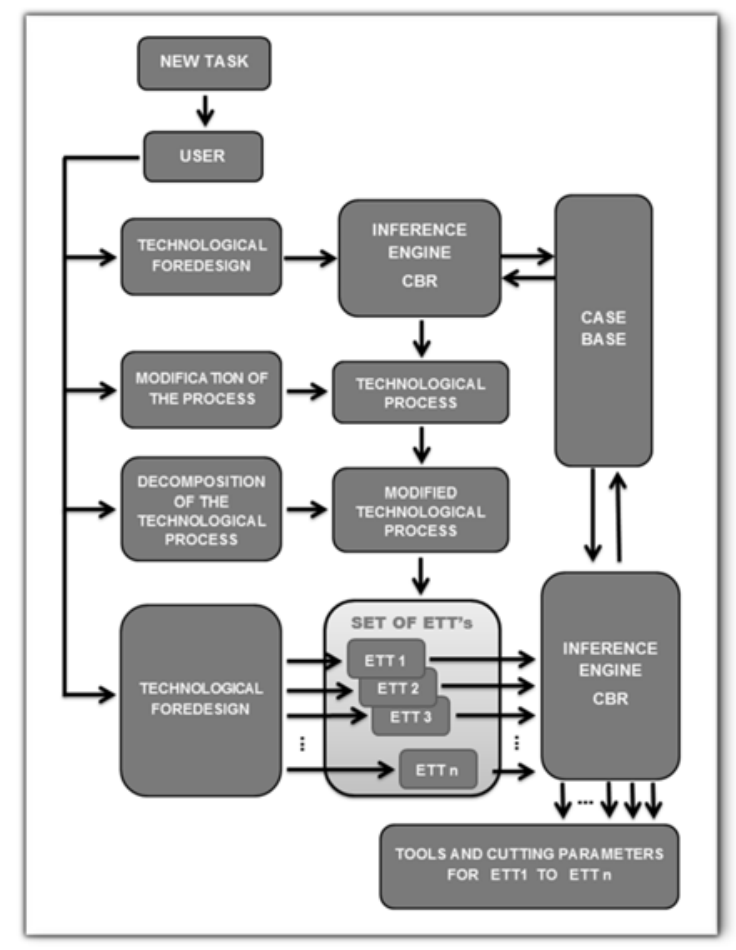

Fig. 2. Algorithm of the system functioning.

The next important step is the selection of machining (cutting) tools and parameters. For this purpose, the adapted technological process (the set of technological activities) is decomposed into so called Elementary Technological Tasks (ETT), for which one must choose the proper cutting tools and parameters. Then, for particular ETT is created the task description $T$ _case. In a subsequent step, with the developed system, are sought analogous cases (ETT), implemented in the past. Basing on these cases the cutting tools and parameters are selected for the currently realized task (ETT). The method, presented in this paper, could be used for supporting the preparation of technological processes for rotationally-symmetrical elements (like shafts, bushes, rings, etc.). Of course, there is the possibility to modify the developed method taking into account other types of elements. 


\subsection{Formalized description of technological process selection}

For the process of selection the cutting tools and machining parameters the formalized description of functioning of this method is as follows. Given is the description of the task, $T$ case, in which the user defines the attributes and weights describing the analyzed technological task.

$$
T \_ \text {case }=\{Z T, P M, P K\}
$$

where:

$Z T$ - technological foredesign,

$P M$ - description of the initial material,

$P K-$ constructional form,

$$
Z T=\left\{A T_{1}, W T_{1}, w_{1}, A T_{2}, W T_{2}, w_{2}, \ldots, A T_{j}, W T_{j}, w_{j},\right\}
$$

where:

$A T_{j}-j$-th attribute describing the technological task,

$W T_{j}$ - value of the $j$-th technological attribute describing the technological task, $w_{j}$-weight of the $j$-th technological attribute describing the technological task.

$$
P K=\{P K z, P K w\}
$$

where:

$P K z$ - outer constructional form,

$P K w$ - inner constructional form.

$$
\begin{aligned}
& P K z=\left\{S z_{1}, S z_{2}, \ldots, S z_{n}\right\} \\
& P K w=\left\{S w_{1}, S w_{2}, \ldots, S w_{n}\right\}
\end{aligned}
$$

where:

$S z_{n}-n$-th step on the element, outer,

$S w_{n}-n$-th step on the element, inner.

$$
\begin{aligned}
& S z=\left\{E O K z_{1}, E O K z_{2}, \ldots, E O K z_{m}\right\} \\
& S w=\left\{E O K w_{1}, E O K w_{2}, \ldots, E O K w_{m}\right\}
\end{aligned}
$$

where:

$E O K z_{m}-m$-th outer constructional feature,

$E O K w_{m}-m$-th inner constructional feature.

$E O K z$ and $E O K w$ are finite sets of typical features of constructional objects which may occur as logical components rotational-symmetric elements.

$$
\begin{aligned}
& E O K z=\left\{A_{E O K z l}, W A_{E O K z l}, A_{E O K z z}, W A_{E O K z 2}, \ldots, A_{E O K z z}, W A_{E O K z z}\right\} \\
& E O K w=\left\{A_{E O K w 1}, W A_{E O K w 1}, A_{E O K w 2}, W A_{E O K w 2}, \ldots, A_{E O K w z}, W A_{E O K w z}\right\}
\end{aligned}
$$

where:

$A_{E O K z z}-\mathrm{z}$-th attribute describing outer constructional feature,

$W A_{E O K z z}-\mathrm{z}$-th value of the attribute describing outer constructional feature,

$A_{E O K w z}-\mathrm{z}$-th attribute describing inner constructional feature,

$W A_{E O K w z}-\mathrm{z}$-th value of the attribute describing inner constructional feature. 
During comparing the geometric form of the analyzed element it is analyzed both the incidence of constructional features as well as their order of occurrence in the analyzed stage (part) of an object [22-27]. It was assumed that the analysis and decomposition of the element runs from the left side of this element. In Fig. 3 is shown the description of an constructional form of an exemplary shaft.

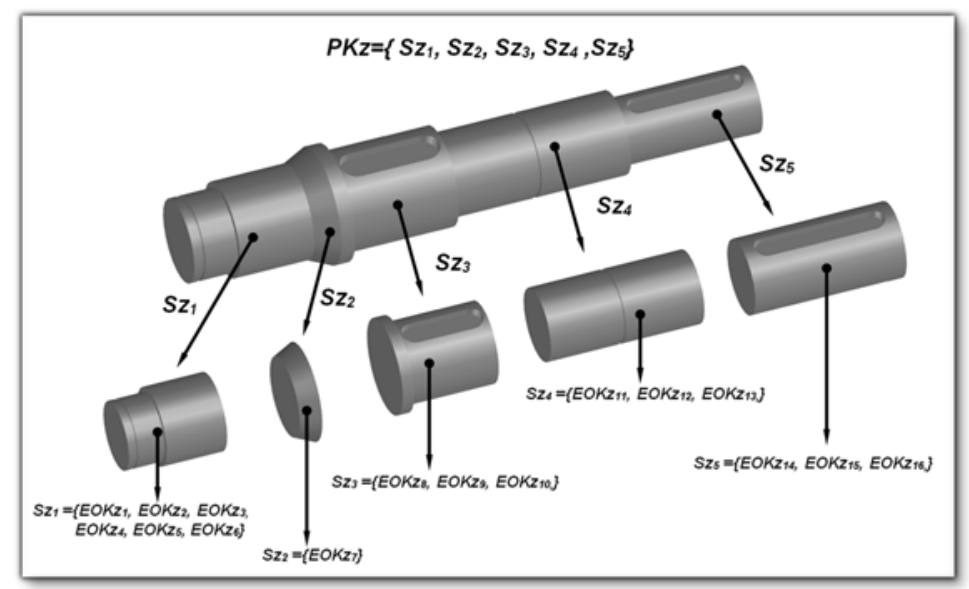

Fig. 3. Description of the constructional form of an exemplary shaft.

After this step the following procedures of the CBR are performed. In the CBR case base is stored a set of cases, Case $_{s}$, which includes the technological solutions (processes) implemented in the past.

$$
\text { Case }_{s}=\left\{\text { case }^{l}\left[T_{-} \text {case }_{1}, P T_{1}\right], \ldots \text { case }^{i}\left[T_{-} \text {case }_{i}, P T_{i}\right]\right\}
$$

where:

case $^{i}\left[T_{\text {case }}, P T_{1}\right]-i$-th technological case,

$T$ case $_{i}$ - description of the $i$-th technological task,

$P \bar{T}_{i}-$ structure of the technological process for the $i$-th case.

Basing on the values of particular attributes and weights, stored in the description $T$ case the calculation mechanism of CBR, according to the formulas (11) and (12), determines the degree of similarity between the task description $T_{-}$case and cases case $e_{i}$ stored in the database.

where:

$$
\begin{gathered}
\left.\operatorname{Sim}\left(T_{-} \text {case, case } e^{i}\right)\right)=1-\operatorname{Dist}\left(T_{-} \text {case }, \text { case }^{i}\right) \\
\operatorname{Dist}\left(T_{-} \text {case }, \text { case }^{i}\right)=\left(\frac{1}{k} \cdot \sum_{j=1}^{k} w_{j}^{2} \cdot\left[T_{-} \text {case }_{j}-\text { case }_{j}^{i}\right]^{2}\right)^{\frac{1}{2}}
\end{gathered}
$$

case $_{j}^{i}$ - value of the $j$-th attribute in the $i$-th case,

$k$ - number of corresponding attributes,

$w_{j}$ - weight coefficient of the $j$-th attribute in the analyzed case. Cases ${ }^{s}$.

Then is generated the set of cases with the required (acceptable) degree of similarity

$$
\operatorname{Cases}^{s}=\left\{\operatorname{case}^{l}\left[T_{\_} \text {case }_{1}, P T_{1}\right], \ldots . \text { case }^{k}\left[T \_ \text {case }_{k}, P T_{k}\right]\right\}
$$


In the next step, the system sorts the chosen solutions, according to the degree of similarity, and creates the ordered set of cases $\operatorname{Cases}_{\mathrm{u}}^{\mathrm{s}}$.

$$
\operatorname{Cases}_{u}^{s}=<\text { case }^{l}\left[T_{-} \text {case }_{1}, P T_{1}\right], \ldots . \text { case }^{k}\left[T_{-} \text {case }_{k}, P T_{k}\right]>
$$

The ordered set $\operatorname{Cases}_{u}^{s}=<\ldots .>$ is the set of the most similar technological processes that could be used in the task currently being under consideration.

\subsection{Formalized description of cutting tools and parameters selection}

For the process of selection the cutting tools and machining parameters the formalized description of functioning of this method is as follows. Given is the description of the task, $T$ case, in which the user defines the attributes and weights describing the analyzed technological task.

$$
T \_ \text {case }=\left\{W A_{1}, w_{1}, W A_{2}, w_{2}, \ldots W A_{j}, w_{j}\right\}
$$

where:

$W A_{j}$ - the value of the $j$-th attribute describing the technological task,

$w_{j}-$ the weight of the $j$-th attribute describing the technological task.

In the CBR database is stored the set of cases Case $_{s}$, which includes technological solutions (used tools and machining parameters) implemented in the past.

$$
\text { Case }_{s}=\left\{\text { case }^{l}\left[T_{\text {_case }}, T_{1}, P_{1}, H_{1}, M_{1}\right], \ldots \text { case }^{i}\left[T \_ \text {case }_{i}, T_{i}, P_{i}, H_{i}, M_{i}\right]\right\}
$$

where:

case $^{i}\left[T_{-}\right.$case $\left._{1}, T_{1}, P_{1}, H_{1}, M_{1}\right]$ - the $i$ - th technological case,

$T$ case $_{i}$ - description of the $i$-th technological case,

$T_{i}$ - the tools description for the $i$ - th technological case,

$P_{i}$ - parameters description for the $i$ - th technological case,

$H_{i}$ - fixing method description for the $i$ - th technological case,

$M_{i}$ - machine tool description for the $i$ - th technological case.

Table 1. Attributes and exemplar values with respect to the $T_{-}$case task description.

\begin{tabular}{|l|l|l|}
\hline Data set & \multicolumn{1}{|c|}{ Attribute } & \multicolumn{1}{c|}{ Exemplar values } \\
\hline T_case & Material & P, M, K, N, S, H \\
\cline { 2 - 3 } & Production & (piece, series, mass) \\
\cline { 2 - 3 } & Machining type & Rough, Medium, Finish \\
\cline { 2 - 3 } & Operation type & (outer/inner) \\
\cline { 2 - 3 } & Outer diameter & (min/-/max) \\
\cline { 2 - 3 } & Inner diameter & (min/-/max) \\
\cline { 2 - 3 } & Feed type & transverse, longitudinal, mixed \\
\cline { 2 - 3 } & Pass & $\mathrm{R}, \mathrm{L}, \mathrm{BB}$ _L, BB_R \\
\cline { 2 - 3 } & Allowance value & (min/max) \\
\cline { 2 - 3 } & Accuracy class & $\mathrm{IT} 7$ \\
\cline { 2 - 3 } & Surface roughness & $\mathrm{Ra}=1.25$ \\
\cline { 2 - 3 } & Goal function & Output, costs \\
\hline
\end{tabular}


Table 2. Register of attributes and exemplar values in relations to the data sets $T_{i}, P_{i}, H_{i}, M_{i}$.

\begin{tabular}{|c|c|c|}
\hline Data set & Attribute & Exemplar values \\
\hline \multirow[t]{10}{*}{$T_{i}$} & Tip form & $\mathrm{R}, \mathrm{S}, \mathrm{C}, \mathrm{D}, \mathrm{V}$ \\
\hline & Tip size & $\mathrm{R}(06), \mathrm{S}(12), \mathrm{C}(25)$ \\
\hline & Nose radius & $04,08,1.2,1.6$ \\
\hline & Clearance angle $\mathrm{Kr}$ & $75^{\circ}, 90^{\circ}, 135^{\circ}$ \\
\hline & Type & Positive, negative \\
\hline & For the type of a material & $\mathrm{P}, \mathrm{M}, \mathrm{K}, \mathrm{N}, \mathrm{S}, \mathrm{H}$ \\
\hline & Tool body type & $\mathrm{A} 90^{\circ}, \mathrm{B} 75^{\circ}, \mathrm{D} 45^{\circ}$ \\
\hline & Type of tip fixing & $\mathrm{C}, \mathrm{D}, \mathrm{M}, \mathrm{W}, \mathrm{P}, \mathrm{S}$ \\
\hline & Tip version & $\mathrm{R}, \mathrm{N}, \mathrm{L}$ \\
\hline & Tip marking & SNMG 120408-R2 \\
\hline \multirow[t]{4}{*}{$P_{i}$} & Cutting speed & $\mathrm{V}_{\mathrm{c}}=\ldots$ \\
\hline & Cutting depth & $a_{p}=\ldots$ \\
\hline & Rotational speed & $\mathrm{N}=\ldots$ \\
\hline & Feed & $\mathrm{f}_{\mathrm{n}}=\ldots$ \\
\hline$H_{i}$ & Fixing type & $\underbrace{1}$ \\
\hline \multirow[t]{2}{*}{$M_{i}$} & Machine tool type & CNC lathe \\
\hline & Machine tool model & AVIAturn 35SM \\
\hline
\end{tabular}

On the basis of values of particular attributes and weights, recorded in the description T_case, the CBR calculation mechanism, according to the formulas (11) and (12), determines the degree of similarity between the task description $T$ case, and cases recorded in the database. Then is generated the set of cases with the desired degree of similarity Cases $^{\text {. }}$.

$$
\text { Cases }^{s}=\left\{\text { case }_{1}\left[T_{-} \text {case }_{l}, T_{1}, P_{l}, H_{l}, M_{1}\right], \ldots . \text { case }_{k}\left[T_{-} \text {case }_{k}, T_{k}, P_{k}, H_{k}, M_{k}\right]\right\}
$$

In the next step, the system sorts the selected solutions according to the degree of similarity and creates the ordered set of cases $\operatorname{Cases}_{u}^{s}$.

$$
\operatorname{Cases}_{u}^{s}=<\operatorname{case}_{1}\left[T_{\text {case }}, T_{1}, P_{l}, H_{l}, M_{1}\right], \ldots . \text { case }_{k}\left[T \_ \text {case }_{k}, T_{k}, P_{k}, H_{k}, M_{k}\right]>
$$

The ordered set Cases $_{u}{ }_{u}=<\ldots .>$ is the set of tools and cutting parameters recommended for the use in the currently considered technological task (ETT). 


\section{Conclusions}

The informatics methods and tools, supporting the manufacturing process, are being increasingly used by contemporary engineers. They accelerate the preparation stage of the technological process and the same the manufacturing process itself. They facilitate "young" technologist's effective and realization of routine tasks. Moreover they allow reducing making errors resulting from monotonous work for the often repeated routine tasks. At the same time they allow the engineer implementing the more creative solutions. Creating the software, basing on the CBR method, is time consuming and absorbing its users, but in the long run it lets to save a lot of time and to eliminate unnecessary errors. Developing such software could be profitable, only if it will be used by a larger number of people for a longer period of time. The proposed method only supports the technologist in its activities. At the current level of development of the informatics methods and systems it cannot be completely automated the production preparation process. It is however possible to effectively support the activities performed at each stage of this process. The man, in contrast to the machine, has the ability to abstract thinking. He is able to combine multiple disciplines of science, as well as to think creatively, not only adapting the earlier cases to current needs.

\section{References}

1. A. Sękala, A. Gwiazda, A Dobrzańska-Danikiewicz, Applied Mechanics and Materials, 657 854-858 (2014)

2. A. Sękala, G. Ćwikła, G. Kost, IOP Conf. Series: Materials Science and Engineering, 95, 012097 (2015)

3. K. Herbuś, P. Ociepka, IOP Conf. Series: Materials Science and Engineering, 95, 012096 (2015)

4. A. Gwiazda, K. Herbuś, G. Kost, P. Ociepka, Solid State Phenomena, 220/221, 479$484(2015)$

5. A. Gwiazda, Adv. Mat. Res. 837 393-98 (2014)

6. P. Ociepka, W. Banaś, K. Herbuś, G. Kost, Advanced Materials Research, 1036, 817822 (2014)

7. W. Banaś, K. Herbuś, G. Kost, A. Nierychlok, P. Ociepka, D. Reclik, Advanced Materials Research, 837, 537-542 (2014)

8. K. Herbuś, G. Kost, D. Reclik, J. Świder, Advanced Materials Research, 837, 582-587 (2014)

9. P. Ociepka, K. Herbuś, IOP Conf. Series: Materials Science and Engineering, 95, $012101(2015)$

10. A. Dymarek, T. Dzitkowski, K. Herbuś, G. Kost, P. Ociepka, Solid State Phenomena, 198, 59-64 (2013)

11. A. Dymarek, T. Dzitkowski, K. Herbuś, G. Kost, P. Ociepka, Advanced Materials Research, 837, 351-356 (2014)

12. K. Herbuś, P. Ociepka, A. Gwiazda, Advanced Materials Research, 1036, 732-736 (2014)

13. K. Herbuś, P. Ociepka, IOP Conf. Series: Materials Science and Engineering, 95, $012084(2015)$

14. G. Ćwikła, C. Grabowik, W. Janik, Applied Mechanics and Materials, 657, 808-812 (2014)

15. A. Gwiazda, R. Knosala, J. of Mat. Pr. Tech., 64/1-3 181-88 (1997)

16. A. Aamodt, E. Plaza; AI Communications. IOS Press, 7, 39-59 (1994) 
17. P. Ociepka, J. Świder, Journal of materials processing technology, 157-158, 221-227 (2004)

18. P. Ociepka, K. Herbuś, A. Gwiazda, Advanced Materials Research, 1036, 1005-1010 (2014)

19. P. Ociepka, K. Herbuś, A. Gwiazda, Advanced Materials Research, 1036, 1011-1016 (2014)

20. P. Ociepka, K. Herbuś, IOP Conf. Series: Materials Science and Engineering, 95, $012100(2015)$

21. P. Ociepka, K. Herbuś, Applied Mechanics and Materials 809-810, 1243-1248 (2015)

22. K. Herbuś, P. Ociepka, A. Gwiazda, Advanced Materials Research, 1036, 1001-1004 (2014)

23. C. Grabowik, G. Ćwikła, W. Janik, Applied Mechanics and Materials, 657, 750-754 (2014)

24. P. Ociepka, K. Herbuś, IOP Conf. Ser.: Mater. Sci. Eng., 145022030 (2016)

25. K. Herbuś, P. Ociepka, IOP Conf. Ser.: Mater. Sci. Eng., 145042018 (2016)

26. K. Herbuś, P. Ociepka, IOP Conf. Ser.: Mater. Sci. Eng., 145052010 (2016)

27. P. Ociepka, K. Herbuś, IOP Conf. Ser.: Mater. Sci. Eng., 145022029 (2016) 